\title{
Mid-Gut Carcinoid Tumour Presenting as Suspected Orbital Metastasis
}

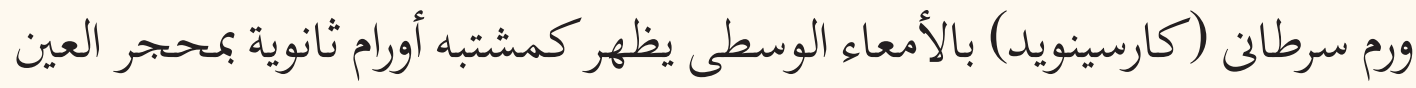

أيمن عبد الحفيظ، سيد محمد على، سلوى محمد سيداحمد، أسما الحسن، نهلة محمد موسى النجار

ABSTRACT: Although metastasis of carcinoid tumours of the intestine is rare, it has been reported in several organs, mainly in the lungs, the liver and less commonly in the orbits. We report a 50-year-old male patient who presented at Hamad General Hospital, Doha, Qatar, in 2016 with central abdominal pain, distention, nausea and vomiting for the previous four days. The patient had unilateral right-sided exophthalmos for two years prior to presentation. Following an abdominal computed tomography (CT) scan and an ultrasound guided biopsy, the patient was diagnosed with extensive multi-focal metastatic carcinoid tumour of the small bowel and mesentery; histopathology confirmed the diagnosis. Subsequently, the patient underwent a laparotomy and small bowel resection and was administered somatostatin therapy. One week postoperatively, the patient developed an acute increase in his right eye exophthalmos. CT, magnetic resonance imaging and scintigraphy scans revealed an orbital metastatic lesion, which probably originated from the previously diagnosed carcinoid tumour. The orbital metastasis was treated with somatostatin therapy and the patient was lost to follow-up when he left the country.

Keywords: Carcinoid Tumor; Orbital Neoplasm; Metastasis; Exophthalmos; Scintigraphy; Case Report; Qatar.

الملخص: بالرغم من ندرة الأورام الثانوية التي تنتج من الأورام السرطانية (كارسينويد) التي تصيب الأمعاء الوسطى إلا ان أن هذه الأورام

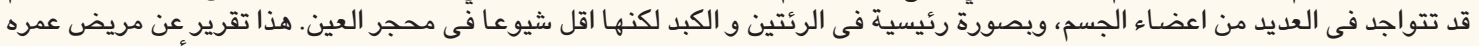

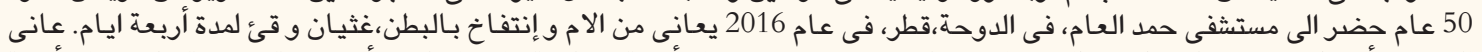

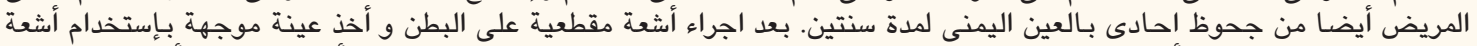

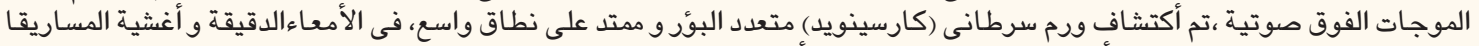

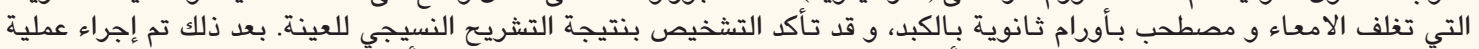

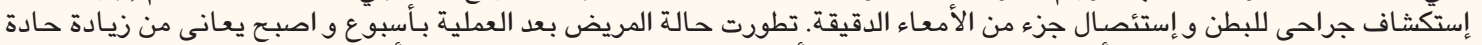

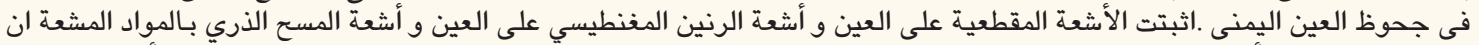

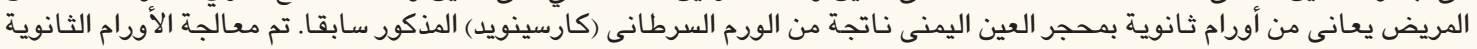

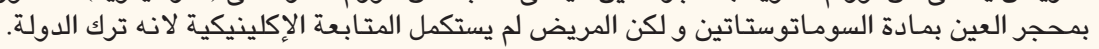
الكلمات المفتاحية: ورم سرطانى؛ ورم بمحجر العين؛ أورام ثانوية؛ جحوظ العين؛ أشعة المسح الذري؛ تقرير حالة؛ قطر.

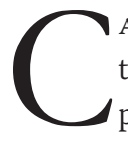
ARCINOID TUMOURS ARE NEUROENDOCRINE tumours (NET) originating mainly from primitive stem cells of the gut, yet they can occur in the lungs, thymus, mediastinum, bronchus, liver, pancreas, ovaries, prostate and kidneys. ${ }^{1-3}$ While originally thought to be of a low grade, metastases are reported in $50-75 \%$ of patients. ${ }^{1}$ The most common locations for gastrointestinal (GI) carcinoids to metastasise are the lymph nodes, liver and bone. ${ }^{2-4}$

Ocular metastasis is a rare finding. Carcinoid tumours that have orbital metastases can be difficult to diagnose and differentiate from primary eye malignancies or metastatic lesions from other malignancies such as lymphoma, breast or GI tract adenocarcinomas and malignant melanoma. ${ }^{5}$

Detection of such lesions can be obtained either by general diagnostic imaging, like computed tomography
(CT) and magnetic resonance imaging (MRI), or the more specific diethylene triamine penta-acetic acid(DTPA)-labelled octreotide analogue scintigraphy and histopathological examination. ${ }^{1}$ Prognosis is generally favourable with treatment options including surgery, external beam radiation, chemotherapy and octreotide and somatostatin analogues. This case report describes an orbital metastasis that originated from a carcinoid tumour of the small bowel and mesentery.

\section{Case report}

A 50-year-old male patient presented at Hamad General Hospital, Doha, Qatar, in 2016 with a history of central abdominal pain, distention, nausea and vomiting for the previous four days. He had no history of flushing, diarrhoea or shortness of breath. The 

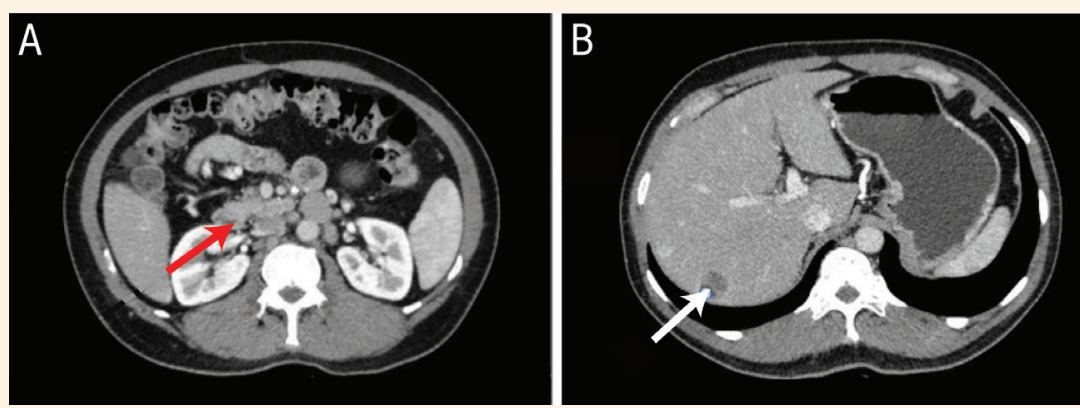

Figure 1: Computed tomography scan of a 50-year-old male patient showing (A) a mass in the mesentery of the small intestine (red arrow) and (B) a lesion in the liver (white arrow).

patient had normal bowel movements and no history of jaundice, fatigue or rectal bleeding. He had unilateral right-sided exophthalmos for two years. Although the patient sought medical advice for the exophthalmos, he did not receive a diagnosis or treatment. There was neither decline of vision nor history of headaches suggestive of raised intracranial pressure.

The patient was mildly dehydrated, yet not distressed, and had normal vital signs. No cervical/ axillary/inguinal lymphadenopathy was detected. The abdomen was not distended; however, mild tenderness in the periumbilical region without guarding and a palpable mass in the epigastric region was observed. The mass was firm, partially mobile and measured $10 \times 10 \mathrm{~cm}$.

The patient's white cell count was $14 \times 10^{3} / \mu \mathrm{L}$ (normal range: $4-7 \times 10^{3}$ cells $/ \mu \mathrm{L}$ ), his haemoglobin level was $15.1 \mathrm{~g} / \mathrm{dL}$ (normal range: $12-16 \mathrm{~g} / \mathrm{dL}$ ) and all other biochemical tests were normal. Abdominal CT scan showed an ill-defined enhancing soft tissue mass in the left upper quadrant of the abdomen arising from the jejunal loops with an exophytic mesenteric soft tissue component causing obstruction of the jejunum along with significant retroperitoneal and mesenteric lymphadenopathy and multiple hyper-vascular liver lesions [Figure 1]. No metastatic lesions were seen in the thorax.

A metastatic intestinal lesion was suspected as the patient had incomplete/partial small bowel obstruction. An ultrasound guided biopsy from the liver lesion showed a metastatic well-differentiated NET with possible GI tract primary involvement. The mitotic count was $<2 / 10$ cells per high power field and the Ki-67 index was $1 \%$. The 5-hydroxyindoleacetic acid levels in a 24-hour urine sample were $250 \mu \mathrm{mol}$ (normal level: $<47$ $\mu \mathrm{mol} / 24$-hour urine sample).

Subsequently, the patient was diagnosed with metastatic carcinoid tumour of the small bowel and mesentery. The case was discussed at a GI cancer multidisciplinary team meeting and it was decided that the tumour would be debulked followed by somatostatin therapy with or without chemotherapy.

The patient underwent an exploratory laparotomy which revealed multiple lesions of various sizes involving the jejunum and proximal ileum; the small bowel mesentery had two large lesions encasing the superior mesenteric artery and a large nodule in the greater omentum. In addition, multiple small nodules were seen on the small bowel serosa and parietal peritoneum and palpable bi-lobar liver lesions [Figure 2]. Segmental small bowel resection from proximal jejunum to mid-ileum was carried out with avoidance of debulking the mesenteric and retroperitoneal lesions to maintain blood supply to the bowels.

Histopathology of the small intestine showed multifocal well-differentiated NET/carcinoid tumour histological grade 1 and a mitotic count of $<2 / 10$ cells per high power field invading through the muscle into the serosa with lymphovascular and perineural invasion. The mesenteric/radial margin was positive for
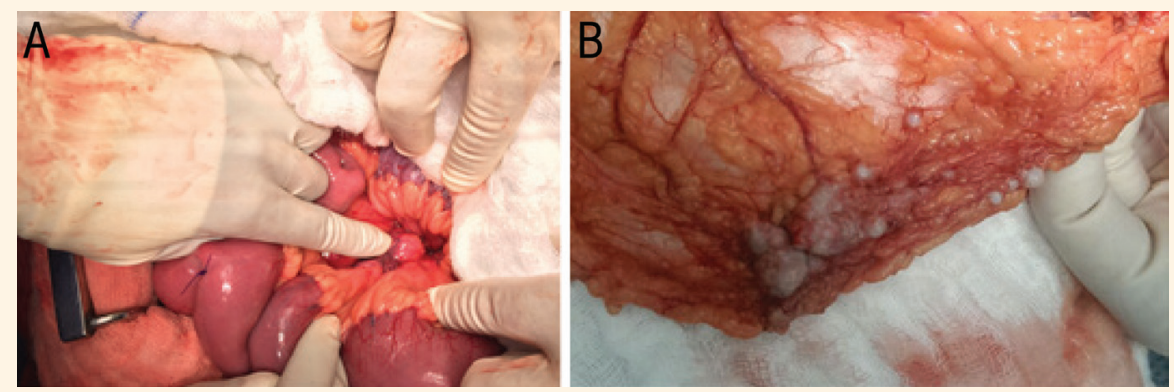

Figure 2: Operative photographs of an exploratory laparotomy of a 50-year-old male patient showing (A) a nodule in the mesentery of the small intestine and (B) multiple nodules in the greater omentum. 


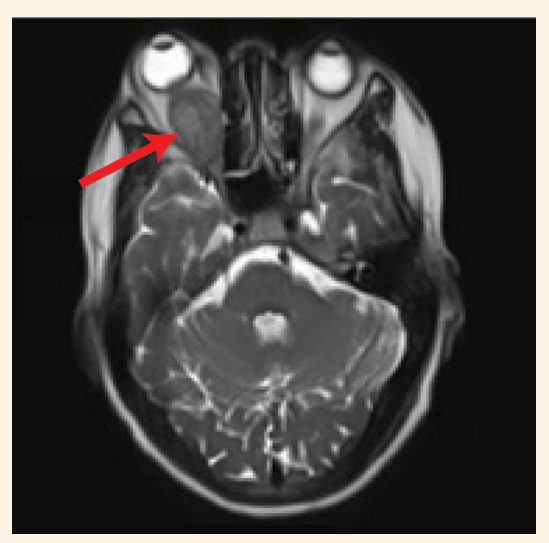

Figure 3: Magnetic resonance imaging scan of the head of a 50-year-old male patient showing a mass in the right orbit (arrow).

presence of the tumour. The pathological staging was pT4 and immunohistochemical stains were positive for synaptophysin and chromogranin, whereas Ki-67 was at $2 \%$ positivity in the tumour cells. The mesentery towards the tumour site was positive for the presence of the carcinoma. The omentum showed multifocal metastatic NET/carcinoid tumour presence with the largest nodule measuring $3.5 \mathrm{~cm}$.

The patient had an uneventful postoperative course, however, on the seventh postoperative day he developed an acute increase in the right eye exophthalmos with deterioration of vision and severe conjunctival and periorbital oedema. Treatment was initiated with tobramycin and dexamethasone, lubricant eye drops and oral prednisone.

An orbital CT scan showed a lobular mass in the inferior aspect of the right orbit measuring $3.1 \times 2.6$ $\mathrm{cm}$; it was not separate from the inferior rectus muscle. An MRI scan showed a heterogeneous intense postcontrast, central breakdown and bright $\mathrm{T} 1 / \mathrm{T} 2$ areas likely representing a haemorrhage within the mass. The lesion was causing proptosis of the right globe and displacement of the optic nerve and superior oblique muscle superiorly [Figure 3]. The acute ocular symptoms were attributed to a haemorrhage inside the orbital tumour, which was suspected to be a metastasis from the carcinoid tumour. The patient's symptoms improved significantly with topical eye drops and steroid treatment.

DTPA-labelled octreotide analogue scintigraphy showed somatostatin-rich neuroendocrine metastasis from the previously diagnosed carcinoid tumour. These lesions were seen in the liver, central abdomen, chest and right orbit [Figure 4]. The patient was treated in the department of oncology with octreotide and was lost to follow-up as he left the country.

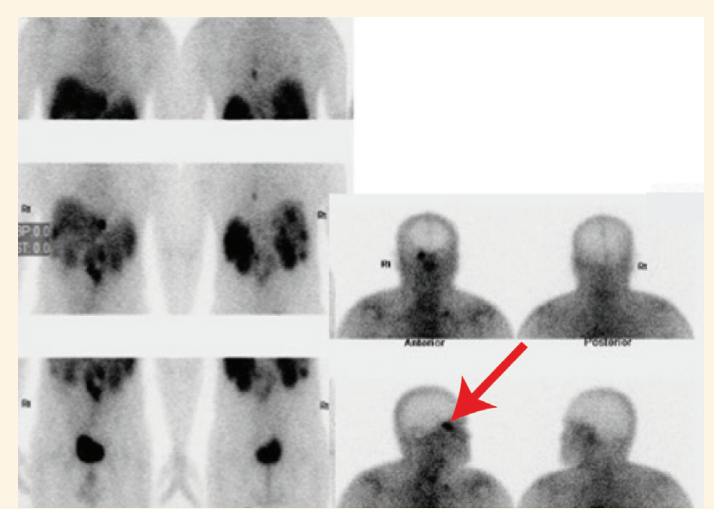

Figure 4: Diethylenetriamine penta-acetic acid-labelled octreotide analogue scintigraphy of a 50-year-old male patient showing right orbital uptake (arrow).

\section{Discussion}

Orbital metastasis is rarely seen and can be associated with lymphoma, carcinoma of the breast or GI tract, melanoma or other secondary orbital tumours. ${ }^{4,6,7}$ Carcinoid tumour is a rare entity and the prevalence of orbital and uveal involvement is approximately $2.2 \%{ }^{1}$

Metastatic spread of carcinoid tumours results in a poor 5 -year survival rate of $<50 \%$ compared to $70 \%$ survival without metastasis. ${ }^{1,3}$ In a case series of 13 patients with orbital metastasis, the reported 5-year survival rate was $72 \%$ and the 10 -year survival rate was $38 \%{ }^{8}$

Ocular metastasis can be suspected when the patient has a previous history of carcinoid tumour, evidence of systemic metastasis and/or clinical symptoms of carcinoid syndrome. The most common presenting symptoms include diplopia (48\%), pain (42\%) and visual loss (30\%), while the most frequent clinical signs include proptosis (63\%), strabismus (62\%) and visual loss (41\%). ${ }^{9}$

While ultrasound and CT scans can help with the diagnosis, MRI scans are considered the gold standard for diagnosing orbital metastasis. ${ }^{1}$ Furthermore, accurate localisation of primary and/or metastatic carcinoid tumours is obtained using scintigraphy with I-123 metaiodobenzylguanidine and 111In-DTPA pentetreotide. ${ }^{1,10}$ Imaging with these modalities provides a sensitivity of $72-87 \%$ whereas specificity may vary. ${ }^{11,12}$ However, histopathology should be used to confirm the diagnosis. Although a biopsy of the orbital lesion was considered gold standard for the definitive diagnosis of the lesion, Das et al. recently refuted this modality and suggested that in the presence of classic radiologic findings, history of mid-gut carcinoid tumour and other metastasis, treatment can be started without a 
biopsy. ${ }^{9,13}$ Orbital biopsy was not done in the current patient.

Radiation and/or chemotherapy are the mainstay of treatment, although surgical excision has also been described in the largest series by Mehta et al. of 13 patients with orbital metastasis. ${ }^{8}$ External beam radiation is a useful and non-invasive treatment modality that has been used in selected cases, particularly for single and symptomatic lesions. ${ }^{14,15}$

Somatostatin analogues (i.e. radio-labelled octreotide) have been widely used to locate primary and metastatic carcinoid tumours and identify individuals who may be eligible for targeted therapy. These radiopharmaceuticals can be used for treating disseminated lesions in various locations especially orbital lesions, as in the current case, and the dose can be repeated if required. Fan et al. reported that chemotherapy can result in regression of choroidal metastasis, while Gragoudas and Carroll mentioned complete response of choroidal metastasis with xenon arc photocoagulation from a bronchial carcinoid tumour. ${ }^{16,17}$ In addition, marked symptomatic improvement and stabilisation of the disease process can be achieved by combining chemotherapy with external beam radiation. ${ }^{1}$ Recently, the Food and Drug Administration approved peptide radionucleotide receptor therapy (PRRT) using ${ }^{177}$ lutentium (Lu)-DOTATATE as systemic cytoreductive and cytostatic treatment modality for mid-gut carcinoid tumours. It involves ${ }^{177} \mathrm{Lu}$, a beta-emitting radionuclide, as the targeted radiation by conjugating with somatostatin receptor analogue. Many reports have documented the symptom relief and stable radiographic findings after ${ }^{177} \mathrm{Lu}-\mathrm{DOTATATE}$ PRRT treatment, particularly in orbital metastasis. ${ }^{6,13,18}$

\section{Conclusion}

Orbital metastasis originating from a carcinoid tumour is rare yet may compromise patients' quality of life. Therefore, early detection and treatment are needed to prevent incapacitating visual loss. A multidisciplinary team approach is required for optimal treatment and patient outcome.

\section{References}

1. Isidori AM, Kaltsas G, Frajese V, Kola B, Whitelocke RA, Plowman PN, et al. Ocular metastases secondary to carcinoid tumors: The utility of imaging with [(123)I] meta-iodobenzylguanidine and [(111)In]DTPA pentetreotide. J Clin Endocrinol Metab 2002; 87:1627-33. https://doi.org/10.1210/jc.87.4.1627.

2. Godwin JD 2nd. Carcinoid tumors. An analysis of 2,837 cases. Cancer 1975; 36:560-9. https://doi.org/10.1002/1097-0142(197 508)36:2<560::aid-cncr2820360235>3.0.co;2-4.
3. Modlin IM, Sandor A. An analysis of 8305 cases of carcinoid tumors. Cancer 1997; 79:813-29. https://doi.org/10.1002/(si ci)1097-0142(19970215)79:4<813::aid-cncr19>3.0.co;2-2.

4. Harbour JW, De Potter P, Shields CL, Shields JA. Uveal metastasis from carcinoid tumor. Clinical observations in nine cases. Ophthalmology 1994; 101:1084-90. https://doi.org/10.1016/s0 161-6420(94)38030-4.

5. Peixoto RDA, Lim HJ, Cheung WY. Neuroendocrine tumor metastatic to the orbit treated with radiotherapy. World J Gastrointest Oncol 2013; 5:177-80. https://doi.org/10.4251/ wjgo.v5.i8.177.

6. Dobson R, Vinjamuri S, Hsuan J, Banks M, Terlizzo M, Weishmann H, et al. Treatment of orbital metastases from a primary midgut neuroendocrine tumor with peptide-receptor radiolabeled therapy using 177 lutetium-DOTATATE. J Clin Oncol 2013; 31:e272-5. https://doi.org/10.1200/JCO.2012.45.8612.

7. Shinder R, Al-Zubidi N, Esmaeli B. Survey of orbital tumors at a comprehensive cancer center in the United States. Head Neck 2011; 33:610-14. https://doi.org/10.1002/hed.21498.

8. Mehta JS, Abou-Rayyah Y, Rose GE. Orbital carcinoid metastases. Ophthalmology 2006; 113:466-72. https://doi.org/10.1016/j. ophtha.2005.10.051.

9. Valenzuela AA, Archibald CW, Fleming B, Ong L, O’Donnell B, Crompton JJ, et al. Orbital metastasis: Clinical features, management and outcome. Orbit 2009; 28:153-9. https://doi.org/10.10 80/01676830902897470.

10. Meunier B, Le Cloirec J, Dazord L, Leveque J, Lesimple T, Tas P, et al. Per operative localization of a carcinoid tumour of the breast using indium-111 pentetreotide and a nuclear surgical probe. Eur J Nucl Med 1995; 22:281-3. https://doi.org/10.1007/ BF01081525.

11. Carnaille B, Nocaudie M, Pattou F, Huglo D, Deveaux M, Marchandise X, et al. Scintiscans and carcinoid tumors. Surgery 1994; 116:1118-21.

12. Hoefnagel CA. Metaiodobenzylguanidine and somatostatin in oncology: Role in the management of neural crest tumours. Eur J Nucl Med 1994; 21:561-81. https://doi.org/10.1007/BF 00173045.

13. Das S, Pineda G, Goff L, Sobel R, Berlin J, Fisher G. The eye of the beholder: Orbital metastases from midgut neuroendocrine tumors, a two institution experience. Cancer Imaging 2018; 18:47. https://doi.org/10.1186/s40644-018-0181-5.

14. Bardenstein DS, Char DH, Jones C, Crawford JB, Miller TR, Riekhof FT. Metastatic ciliary body carcinoid tumor. Arch Ophthalmol 1990; 108:1590-4. https://doi.org/10.1001/archo pht.1990.01070130092038.

15. Rush JA, Waller RR, Campbell RJ. Orbital carcinoid tumor metastatic from the colon. Am J Ophthalmol 1980; 89:636-40. https://doi.org/10.1016/0002-9394(80)90279-2.

16. Fan JT, Ortiz RG, Buettner H. Regression of choroidal metastases from a bronchial carcinoid tumor after chemotherapy with cisplatin and etoposide. Am J Ophthalmol 1994; 117:111-13. https://doi.org/10.1016/s0002-9394(14)73026-0.

17. Gragoudas ES, Carroll JM. Multiple choroidal metastasis from bronchial carcinoid treated with photocoagulation and proton beam irradiation. Am J Ophthalmol 1979; 87:299-304. https:// doi.org/10.1016/0002-9394(79)90067-9.

18. Makis W, McCann K, McEwan AJ. Orbital metastases of neuroendocrine tumors treated with 177Lu-DOTATATE PRRT or 131I-MIBG therapies. Clin Nuc Med 2016; 41:137-41. https://doi.org/10.1097/RLU.0000000000001008. 